\title{
Sudden unexpected death in epilepsy: an important concern
}

\author{
Fulvio Alexandre Scorza,' Roberta Monterazzo Cysneiros," Marly de Albuquerque,' Marcello Scattolini,' \\ Ricardo Mario Arida"I \\ 'Experimental Neurology, Federal University of São Paulo/Paulista School of Medicine, (UNIFESP/EPM), São Paulo, Brazil. "Laboratory of Neurobiology, \\ Post-Graduate Program in Development Disorders from the Center of Biological Sciences and Health of Mackenzie University, São Paulo, Brazil. \\ I'I Department of Physiology, Federal University of São Paulo/Paulista School of Medicine, (UNIFESP/EPM), São Paulo, Brazil.
}

Epilepsy is one of the most common neurologic problems worldwide. Unfortunately, individuals with epilepsy are at higher risk of death than the general population, and sudden unexpected death in epilepsy is the most important direct epilepsy-related cause of death. In this review article, our research group focused on the risk factors, mechanisms and preventative measures obtained from clinical and experimental studies on sudden unexpected death in epilepsy.

KEYWORDS: Epilepsy; Seizures; Sudden unexpected death in epilepsy; Heart; Brain.

Scorza FA, Cysneiros RM, de Albuquerque M, Scattolini M, Arida RM. Sudden unexpected death in epilepsy: an important concern. Clinics. 2011;66(S1):65-69.

Received for publication on December 27, 2010; Accepted for publication on January 11, 2011

E-mail: scorza.nexp@epm.br

Tel.: 551155492064

\section{EPILEPSY: GENERAL ASPECTS}

Epilepsy is one of the most prevalent neurologic conditions and it knows no age, racial, social, geographic or national boundaries. ${ }^{1}$ In the USA, about 100,000 new cases of epilepsy are diagnosed per year. ${ }^{2,3}$ In the UK, at least 300,000 people are currently being treated for epilepsy. ${ }^{4}$ From an epidemiologic point of view, some studies suggest that between $70 \%$ and $80 \%$ of people with epilepsy will go into remission, while the remaining patients continue to have seizures, even under treatment with the currently available therapies. ${ }^{5-7}$ More consistent risk factors for epilepsy are cerebrovascular disease, brain tumors, alcohol, traumatic head injuries, cortical development malformation, genetic inheritance, and infections of the central nervous system. In resource-poor countries, endemic infections, such as malaria and neurocysticercosis, seem to be major risk factors. ${ }^{8}$ By definition, epilepsies are characterized by spontaneous recurrent seizures caused by focal or generalized paroxysmal changes in neurologic functions triggered by abnormal electrical activity in the cortex. ${ }^{9}$ As it involves hyperexcitable neurons, a basic assumption links the pathogenesis of epilepsy and the generation of synchronized neuronal activity with an imbalance between inhibitory [g-aminobutyric acid (GABA)-mediated] and excitatory (glutamate-mediated) neurotransmission (the more favorable assumption). ${ }^{10}$ In general terms, seizures and epilepsy are usually divided into two groups: partial and generalized. Partial, or focal, seizures have clinical or electroencephalography (EEG) evidence of local onset and may spread

Copyright (c) 2011 CLINICS - This is an Open Access article distributed under the terms of the Creative Commons Attribution Non-Commercial License (http:// creativecommons.org/licenses/by-nc/3.0/) which permits unrestricted noncommercial use, distribution, and reproduction in any medium, provided the original work is properly cited. to other parts of the brain during a seizure, while generalized seizures begin simultaneously in both cerebral hemispheres. ${ }^{8}$ Although progress continues to be made in relation to experimental design, clinical research and medical management of epilepsy (including the development of a number of new antiepileptic drugs), ${ }_{1}^{1}$ epilepsy, on the whole, remains a significant clinical problem that requires early and effective treatment.

\section{SUDDEN UNEXPECTED DEATH IN EPILEPSY}

\section{Overview}

Although early mortality series over the past few centuries reported deaths from status epilepticus to be more common, deaths associated with sudden unexpected death in epilepsy (SUDEP) were also recognized. ${ }^{11}$ For instance, by the afternoon of 19 June 1773, Patsy Custis was dead at the age of $17 .^{12}$ Patsy Custis, George Washington's stepdaughter, died suddenly during a brief seizure, and her death may be one of the first well-documented, witnessed descriptions of SUDEP, unwittingly penned by George Washington. ${ }^{12}$ Furthermore, in 1904, Spratling described that epilepsy 'destroys life suddenly and without warning through a single, brief attack... and does so in from 3 to $4 \%$ of all who suffer from it'. ${ }^{11,13}$ Unfortunately, this mysterious affliction is still present today and each year about 1 in a 1000 patients with chronic epilepsy die suddenly, unexpectedly, and without explanation, even after postmortem examination. ${ }^{14}$ Thus, epilepsy is considered to be associated with a two- to three-fold increase in mortality compared to the general population, and SUDEP is the most important direct epilepsy-related cause of death. ${ }^{8}$

\section{Definitions}

The lack of autopsy findings and the rarely witnessed cases of SUDEP pose difficulties with regard to definitions 
of SUDEP. SUDEP was defined by precise criteria that were approved in 1997 by an expert panel. ${ }^{15}$ Although it has proved useful, this workable SUDEP definition is adopted widely, but not universally. ${ }^{11}$ In general terms, SUDEP is defined as sudden, unexpected, witnessed or unwitnessed, nontraumatic and nondrowning death in patients with epilepsy, with or without evidence of a seizure and excluding documented status epilepticus, in which postmortem examination does not reveal a toxicologic or anatomical cause of death. ${ }^{15}$

\section{Incidence}

The reported incidence of SUDEP is quite variable, largely because of differences in patient populations, study design, level of documentation and the criteria for defining SUDEP. ${ }^{16,17}$ To date, SUDEP is responsible for $7.5-17 \%$ of all epilepsy deaths and has an incidence among adults of between 1:500 and 1:1000 patients per year. ${ }^{18}$

\section{Risk Factors}

Whereas many disorders can be largely prevented by avoidance or correction of risk factors, currently known risk factors of SUDEP are not as readily modifiable for the majority of patients. ${ }^{19-21}$ Knowledge of the risk factors underlying SUDEP could help investigations into its pathophysiologic mechanisms. ${ }^{22}$ A number of associated factors for SUDEP have been reported but the results are not wholly consistent between studies. In addition, epileptologists are in agreement that SUDEP is mainly, but not exclusively, a problem for patients with chronic uncontrolled epilepsy. ${ }^{11}$ The other important risk factors include the presence of generalized tonic-clonic seizures (GTCS), duration of the seizure disorder ranging from 15 to 20 years, early onset of epilepsy, antiepileptic medication (polytherapy with antiepileptic drugs), young age and winter temperatures. ${ }^{11,22,23}$

\section{Mechanisms}

Understanding the mechanisms underlying SUDEP may lead to the identification of previously unrecognized risk factors that are more amenable to correction and key to prevention. ${ }^{11,18}$ Although different mechanisms may play separate roles in different cases, ${ }^{23}$ the two major domains of potential mechanisms of SUDEP are autonomic, i.e. cardiovascular and respiratory. ${ }^{20}$ Pulmonary abnormalities, such as increased lung weight, pulmonary congestion, or edema appear frequently in postmortem examinations of SUDEP victims. ${ }^{20}$ Notably, both central and obstructive apnea can occur during, or immediately after, a seizure. ${ }^{24}$ Moreover, obstructive apnea will usually complicate a GTCS, whereas central apnea may occur during both partial and generalized seizures. ${ }^{24,25}$ Furthermore, there are clear indications that cardiac mechanisms play a role in SUDEP. Potential pathomechanisms comprise cardiac arrhythmia during, and between, seizures, antiepileptic drugs that have arrhythmogenic characteristics, or transmission of the epileptic activity via the autonomic nervous system to the heart. ${ }^{17}$ It is also important to note that a number of postmortem, ictal and interictal cardiac abnormalities account for the possibility of seizure-induced cardiogenic SUDEP. ${ }^{17,24}$ For example, postmortem examinations in patients who died of SUDEP have found dilated and heavier hearts than normal. ${ }^{17,26,27}$ Furthermore, some pathologic alterations in the hearts of patients who died of SUDEP have also been described, such as fibrosis of the walls of small coronary arteries, cardiomyocyte atrophy, myofibrillar degeneration, edema of the conductive tissue and morphological abnormalities of the cardiac conduction system. ${ }^{17,26,27}$ These abnormalities may be the consequence of repeated hypoxemia and/or associated with the increase of catecholamines during ictal sympathetic storm. $17,26,28$ Several studies assessed the frequency and character of ictal cardiac rhythm during seizures. ${ }^{17,24,26,28}$ The most compelling evidence derived from the presence of ictal arrhythmias. ${ }^{24}$ For instance, Nashef et al. recorded non-invasively ictal cardiorespiratory variables in patients with epilepsy. ${ }^{25}$ The authors found an increase in heart rate in $91 \%$ of 41 seizures monitored, and a transient bradycardia in 5 seizures (4 patients). ${ }^{25}$ Furthermore, Nei et al. evaluated the electrocardiographic (ECG) changes in 51 seizures in 43 patients with refractory epilepsy. ${ }^{29}$ They showed that $70 \%$ of patients had either ECG abnormalities $(16 \%)$ or tachycardia $(30 \%)$, or both $(23 \%)$, during the ictal and/or post-ictal period. All the authors suggest that these changes may be relevant to the pathophysiology of SUDEP. ${ }^{29}$ Concerning cardiovascular abnormalities between seizures, some research groups have described interesting results. In 1993, Drake and co-workers reviewed resting ECGs in 75 patients with epilepsy and compared ventricular rate, PR interval, QRS duration, and QT interval corrected for heart rate (QTC) with normal ECGs recorded in age-matched patients without cardiac or neurologic disorders. ${ }^{30}$ Epilepsy patients showed a higher heart rate and a longer QT duration than ECGs recorded in age-matched patients without a cardiac or neurologic disorder. However, heart rate and QT duration were not outside the normal range. ${ }^{30}$ In 2003, Tigaran et al. investigated whether patients with drug refractory epilepsy had cardiovascular abnormalities that may be related to a high frequency of sudden death. ${ }^{31}$ In their study, 23 subjects underwent comprehensive cardiovascular evaluations (ECG, Holter-monitoring, echocardiography, ergometric exercise test and myocardial scintigraphy, and, if abnormalities were found, coronary angiography) before and during video-EEG monitoring. They found ST-segment depression in $40 \%$ of patients associated with a higher maximum heart rate during seizures, suggesting that cardiac ischemia may occur in these patients. ${ }^{31}$ Although interictal changes in heart rate variability have been described in patients with epilepsy, their contribution to SUDEP remains to be determined.

From an experimental perspective, although much has been learned from animal studies about structural, chemical and physiologic changes that contribute to seizures and epilepsy, the development of experimental preparations that closely model the human SUDEP phenomenon is essential, as they could provide vital information to aid elucidation of the pathogenetic mechanisms of SUDEP and stimulate investigation into possible therapeutic strategies. ${ }^{32}$ Following this line of reasoning, the experience of our research group makes us increasingly believe that some chronic models of temporal lobe epilepsy are important tools for the study of cardiovascular abnormalities in epilepsy, and may even be relevant for understanding the SUDEP phenomenon. In 2005, we used the pilocarpine model in order to evaluate the heart rate of rats with epilepsy in vivo (ECG) and in an isolated ex vivo preparation (Langendorf preparation). ${ }^{27}$ Briefly, we demonstrated a significant increase in baseline heart rate 
in vivo of animals with epilepsy [346 \pm 7 beats per minute (bpm)] when compared with control group animals $(307 \pm 9 \mathrm{bpm})$. Interestingly, we did not find differences in the isolated ex vivo studies (control animals: $175 \pm 7 \mathrm{bpm}$; animals with epilepsy: $176 \pm 6 \mathrm{bpm})$, suggesting that autonomic modulation of the heart is changed in rats with epilepsy, which could explain the appearance and maintenance of an increased basal heart rate in these animals. ${ }^{27}$ Recently, we also analyzed the heart rate in rats subjected to electrical kindling of the amygdala. ${ }^{33}$ The main purpose of our study was to evaluate changes in baseline heart rate and heart rate responses during stage 5 of kindling, which corresponds to generalized seizures. ${ }^{33}$ Briefly, the animals did not show significant differences in basal heart rate before or after electrode implantation. On the other hand, basal heart rate was higher during stage 5 of kindling, possibly resulting from sympathetic activation caused by the epileptic condition. Furthermore, we also observed that an intense bradycardia occurred at the beginning of seizure, followed by a rebound tachycardia. Interestingly, our results indicate that the intensity of the tachycardia is directly related to the number of generalized seizures. These results show that repeated GTCS directly affect sympathetic outflows. ${ }^{33}$

\section{Prevention of SUDEP}

Unfortunately, although we still are unable to prevent or even completely reverse some cases of epilepsy, preventive measures have been proposed in order to minimize the occurrence of SUDEP, ${ }^{34}$ although strict evidence for their effectiveness is still lacking.

\section{Good control of seizures is the first line of defense}

The most effective conventional way to control seizures is antiepileptic drug therapy. Medication adherence involves factors such as getting prescriptions filled, remembering to take medication on time and understanding the instructions. If that approach is unsuccessful, other therapies that could be considered include epilepsy surgery and vagus nerve stimulation. ${ }^{11,23,35}$

\section{Reduction of stress}

The majority of studies define stress as circumstances that people would find stressful. ${ }^{36}$ It has been established that a diagnosis of epilepsy may bring with it many potential stresses, many of which are chronic. ${ }^{36}$ The seizures, and in particular their unpredictability, are a major source of stress for a patient with epilepsy. ${ }^{36}$ Furthermore, stress may cause people to forget to take medication, leading to an increase in seizures. Stress can trigger an increase in the breathing rate (hyperventilation), provoking seizures in certain patients, especially those with absence seizures; negative emotions related to stress (worry or fright) may cause seizures, especially in people with temporal lobe epilepsy. Stress also increases cortisol levels, which may also influence seizure activity. ${ }^{36}$

\section{Participation in physical activity and sports}

People with epilepsy should have the same benefits as others from the positive effects on maximal aerobic and work capacity, body weight and self-esteem. Furthermore, as physical activity has been considered as having an anticonvulsant effect, it is rational to believe that regular physical activity (with appropriate professional supervision) may attenuate the frequency of seizures and cardiac abnormalities that could predispose patients to SUDEP. ${ }^{37,38}$

\section{Supervision at night}

Night-time supervision involves the presence of an individual of normal intelligence and who is at least 10 years old, or the use of special precautions (bed seizure monitor or breathing alarm), in the bedroom. ${ }^{39,40}$ Bed seizure monitors or breathing alarms are designed to detect nocturnal GTCS. These alert family members to the presence of a seizure, allowing them to render any aid necessary in the ictal or post-ictal settings. ${ }^{39,40}$

\section{Family members knowing cardiopulmonary resuscitation (CPR) techniques and the basics of defibrillator use}

More work is required in this area; however, the use of these techniques by trained family members can lead to improved survival for victims of cardiac arrest that could occur during ictal or post-ictal periods.

\section{Omega-3 supplementation}

Several experimental and clinical studies have clearly demonstrated that complementary medical therapies, ${ }^{41}$ especially omega-3 fatty acids, are often tried by neurologists to control seizures. ${ }^{42}$ The first randomized trial of omega-3 supplementation in patients with chronic epilepsy were encouraging, demonstrating a transient effect on seizure control that was not confirmed by other research group, but additional trials are required. ${ }^{42,43}$ Although these results did not totally confirm that omega- 3 fatty acids supplementation reduced the frequency of epileptic seizures in patients with refractory epilepsy, they established the safety of omega-3 supplementation in people with epilepsy. ${ }^{42}$ Using the pilocarpine model of epilepsy, a valuable tool to study the pathogenesis of temporal lobe epilepsy in the human condition, it was recently demonstrated that chronic treatment with omega-3 promotes neuroprotection and positive plastic changes in the brain of rats with epilepsy. ${ }^{44,45}$ Taking all these data together, there is now great interest in n-3 fatty acids for use in the prevention of SUDEP. ${ }^{4,46}$ In this sense, as omega-3 fatty acids per se have been shown to reduce cardiac arrhythmias and sudden cardiac deaths, it was proposed that omega-3 fatty acid supplementation in patients with refractory seizures may reduce seizures, seizure-associated cardiac arrhythmias and, hence, SUDEP. ${ }^{4,46}$

The human body cannot synthesize omega- 3 fatty acids so it must be obtained from food. In fact, the intake of longchain omega-3 fatty acids, commonly found in fish and fish oil, is a good way to improve the development of the brain (from the composition of cell membranes to cerebral function) and all omega-3 fatty acids are important for treating or preventing cardiovascular and neurologic diseases, including epilepsy. ${ }^{4,46-49}$ In this context, eating fish is a good souce of long-chain omega-3 fatty acids. However, it is important to remember that some types of fish (older, larger and predatory fish) may contain high levels of contaminants, mainly methylmercury, that are toxic to humans. Thus, the best seafood choices are those with non-predatory characteristics (e.g. anchovies, Atlantic herring, Atlantic mackerel, wild salmon, sardines, trout), whilst predatory fish should be avoided (tuna, shark, 
tilefish, swordfish). ${ }^{50-53}$ On the other hand, for individuals who want a diet with zero methylmercury but would like to enjoy the benefits of omega- 3 fatty acids, there are fish oil supplements or other foods such as walnuts or oils (flax, canola and soybean). ${ }^{51,54}$ Despite the originality and the health advantages of fish that are conferred by its high omega-3 fatty acids content to patients with refractory epilepsy, neurologists are clear that nutritional therapy is not a substitute for anticonvulsant medications. ${ }^{55}$

\section{FINAL CONSIDERATIONS}

Attempting to solve these problems is never an easy task; epileptologists should establish a task force to assess the current state of knowledge on SUDEP (clinical management, research directions, and educational, social and cultural efforts). Furthermore, we agree with suggestions ${ }^{14}$ that, if there is a reasonable chance of preventing SUDEP, it must be discussed with all patients with epilepsy who are at highest risk of SUDEP. Possible strategies that patients with epilepsy and their families can take to try to reduce SUDEP risk could then be explained by the physician.

Thus, drawing up a list of all the current problems, evaluating the ones that merit fixing and assessing the problems that are actually fixable should provide a promising future. Finally, as eastern culture states: 'Great achievements are possible when you give importance to small beginnings'.

\section{ACNOWLEDGEMENTS}

The authors thank FAPESP, CInAPCe-FAPESP, FAPESP/CNPq/MCTInstituto Nacional de Neurociência Translacional and CNPq for supporting their studies.

\section{REFERENCES}

1. de Boer HM, Mula M, Sander JW. The global burden and stigma of epilepsy. Epilepsy Behav. 2008;12:540-6, doi: 10.1016/j.yebeh.2007.12. 019.

2. Begley CE, Annegers JF, Lairson LB, Reynolds TF. Epilepsy incidence, prognosis, and use of medical care in Houston, Texas, and Rochester, Minnesota. Epilepsia. 1998;39:222

3. Annegers JF. Epidemiology of epilepsy. In: Wyllie E, editor. The treatment of epilepsy: principles and practice. 2nd ed. Baltimore: Williams \& Wilkins; 1997. pp. 165-72.

4. Yuen AW, Sander JW. Is omega-3 fatty acid deficiency a factor contributing to refractory seizures and SUDEP? A hypothesis. Seizure. 2004;13:104-7.

5. Kwan P, Sander JW. The natural history of epilepsy: an epidemiological view. J Neurol Neurosurg Psychiatry. 2004;75:1376-81, doi: 10.1136/ jnnp.2004.045690.

6. Sander JW. Some aspects of prognosis in the epilepsies: a review. Epilepsia. 1993;34:1007-16, doi: 10.1111/j.1528-1157.1993.tb02126.x.

7. Halatchev VN. Epidemiology of epilepsy-recent achievements and future. Folia Medica (Plovdiv). 2000;42:17-22.

8. Duncan JS, Sander JW, Sisodiya SM, Walker MC. Adult epilepsy. Lancet. 2006;367:1087-100, doi: 10.1016/S0140-6736(06)68477-8.

9. Dichter MA. Emerging insights into mechanisms of epilepsy: implications for new antiepileptic drug development. Epilepsia. 1994;35:S51-7, doi: 10.1111/j.1528-1157.1994.tb05956.x.

10. Dalby NO, Mody I. The process of epileptogenesis: a pathophysiological approach. Curr Opin Neurol. 2001;14:187-92, doi: 10.1097/00019052200104000-00009.

11. Tomson T, Nashef L, Ryvlin P. Sudden unexpected death in epilepsy: current knowledge and future directions. Lancet Neurol. 2008;7:1021-31, doi: 10.1016/S1474-4422(08)70202-3.

12. Doherty MJ. The sudden death of Patsy Custis, or George Washington on sudden unexplained death in epilepsy. Epilepsy Behav. 2004;5:598-600, doi: 10.1016/j.yebeh.2004.03.010.

13. Spratling WP. Prognosis. In: Epilepsy and its treatment. Philadelphia: W B Saunders, 1904:304.
14. Hirsch LJ, Hauser WA. Can sudden unexplained death in epilepsy be prevented? Lancet. 2004;364:2157-8, doi: 10.1016/S0140-6736(04)17605-8.

15. Nashef L. Sudden unexpected death in epilepsy: terminology and definitions. Epilepsia. 1997;38:S6-8, doi: 10.1111/j.1528-1157.1997. tb06130.x.

16. Nei M, Hays R. Sudden unexpected death in epilepsy. Curr Neurol Neurosci Rep. 2010;10:319-26, doi: 10.1007/s11910-010-0116-4.

17. Stollberger C, Finsterer J. Cardiorespiratory findings in sudden unexplained/unexpected death in epilepsy (SUDEP). Epilepsy Res. 2004;59:51-60, doi: 10.1016/j.eplepsyres.2004.03.008.

18. Schuele SU, Widdess-Walsh P, Bermeo A, Lüders HO. Sudden unexplained death in epilepsy: the role of the heart. Cleve Clin J Med. 2007;74:S121-27, doi: 10.3949/ccjm.74.Suppl_1.S121.

19. So EL. Demystifying sudden unexplained death in epilepsy: are we close? Epilepsia. 2006;47:87-92, doi: 10.1111/j.1528-1167.2006.00667.x.

20. So EL. What is known about the mechanisms underlying SUDEP? Epilepsia. 2008;49:93-8, doi: 10.1111/j.1528-1167.2008.01932.x.

21. Tellez-Zenteno JF, Ronquillo LH, Wiebe S. Sudden unexpected death in epilepsy: evidence-based analysis of incidence and risk factors. Epilepsy Res. 2005;65:101-15, doi: 10.1016/j.eplepsyres.2005.05.004.

22. Scorza FA, de Albuquerque M, Arida RM, Cavalheiro EA. Sudden unexpected death in epilepsy: Are winter temperatures a new potential risk factor? Epilepsy Behav. 2007;10:509-10, doi: 10.1016/j.yebeh.2007.02. 012.

23. Surges R, Thijs RD, Tan HL, Sander JW. Sudden unexpected death in epilepsy: risk factors and potential pathomechanisms. Nat Rev Neurol. 2009; 5:492-504, doi: 10.1038/nrneurol.2009.118.

24. Ryvlin P, Montavont A, Kahane P. Sudden unexpected death in epilepsy: from mechanisms to prevention. Curr Opin Neurol. 2006;19:194-99, doi: 10.1097/01.wco.0000218238.90711.f4

25. Nashef L, Walker F, Allen P, Sander JW, Shorvon SD, Fish R. Apnoea and bradycardia during epileptic seizures: relation to sudden death in epilepsy. J Neurol Neurosurg Psychiatry. 1996;60:297-300, doi: 10.1136/ jnnp.60.3.297.

26. Bell GS, Sander JW. Sudden unexpected death in epilepsy. Risk factors, possible mechanisms and prevention: a reappraisal. Acta Neurol Taiwan. 2006;15:72-83.

27. Colugnati DB, Gomes PA, Arida RM, de Albuquerque M, Cysneiros RM, Cavalheiro EA, et al. Analysis of cardiac parameters in animals with epilepsy: possible cause of sudden death? Arq Neuropsiquiatr. 2005;63:1035-41, doi: 10.1590/S0004-282X2005000600023.

28. Lathers CM, Schraeder PL, Bungo MW. The mystery of sudden death: mechanisms for risks. Epilepsy Behav. 2008; 12:3-24, doi: 10.1016/j. yebeh.2007.09.016

29. Nei M, Ho RT, Sperling MR. EKG abnormalities during partial seizures in refractory epilepsy. Epilepsia. 2000;41:542-8, doi: 10.1111/j.1528-1157. 2000.tb00207.x.

30. Drake ME, Reider CR, Kay A. Electrocardiography in epilepsy patients without cardiac symptoms. Seizure. 1993;2:63-5, doi: 10.1016/S10591311(05)80104-9.

31. Tigaran S, Molgaard H, McClelland R, Dam M, Jaffe AS. Evidence of cardiac ischemia during seizures in drug refractory epilepsy patients. Neurology. 2003;60:492-5.

32. Striano P, Zara F. Epilepsy: a 'going ape' model for SUDEP? Nat Rev Neurol. 2009;12:639-40, doi: 10.1038/nrneurol.2009.190.

33. Pansani AP, Colugnati DB, Sonoda YFE, Arida RM, Cravo SL, Schoorlemmer $\mathrm{GH}$, et al. Tachycardias and sudden unexpected death in epilepsy: a gold rush by an experimental route. Epilepsy Behav. 2010;19:546-7, doi: 10.1016/j.yebeh.2010.08.019.

34. Scorza FA, Arida RM, Terra VC, Cavalheiro EA. What can be done to reduce the risk of SUDEP? Epilepsy Behav. 2010;18:137-8, doi: 10.1016/j. yebeh.2010.04.046.

35. Scorza FA, Colugnati DB, Pansani AP, Sonoda EY, Arida RM, Cavalheiro EA. Preventing tomorrow's sudden cardiac death in epilepsy today: what should physicians know about this? Clinics. 2008;63:389-94, doi: 10. 1590/S1807-59322008000300017.

36. Yuen AW, Thompson PJ, Flugel D, Bell GS, Sander JW. Mortality and morbidity rates are increased in people with epilepsy: is stress part of the equation? Epilepsy Behav. 2007;10:1-7, doi: 10.1016/j.yebeh.2006.09.004.

37. Arida RM, Scorza FA, Scorza CA, Cavalheiro EA. Is physical activity beneficial for recovery in temporal lobe epilepsy? Evidences from animal studies. Neurosci Biobehav Rev. 2009;33:422-31, doi: 10.1016/j.neubiorev. 2008.11.002.

38. Arida RM, Scorza CA, Schmidt B, de Albuquerque M, Cavalheiro EA, Scorza FA. Physical activity in sudden unexpected death in epilepsy: much more than a simple sport. Neurosci Bull. 2008;24:374-80, doi: 10 1007/s12264-008-0805-z.

39. Langan Y, Nashef L, Sander JW. Case-control study of SUDEP. Neurology. 2005;64:1131-3.

40. Nashef L, Ryvlin P. Sudden unexpected death in epilepsy (SUDEP): update and reflections. Neurol Clin. 2009;27:1063-74, doi: 10.1016/j.ncl. 2009.08.003.

41. Schachter SC. Complementary and alternative medical therapies. Curr Opin Neurol. 2008;21:184-9, doi: 10.1097/WCO.0b013e3282f47918. 
42. DeGiorgio CM, Miller P. n-3 fatty acids (eicosapentanoic and docosahexanoic acids) in epilepsy and for the prevention of sudden unexpected death in epilepsy. Epilepsy Behav. 2008;13:712-3, doi: 10.1016/j.yebeh.2008.06.017.

43. Yuen AW, Sander JW, Fluegel D, Patsalos PN, Bell GS, Johnson T, Koepp MJ. Omega-3 fatty acid supplementation in patients with chronic epilepsy: a randomized trial. Epilepsy Behav. 2005;7:253-8, doi: 10. 1016/j.yebeh.2005.04.014

44. Ferrari D, Cysneiros RM, Scorza CA, Arida RM, Cavalheiro EA, Almeida ACG, et al. Neuroprotective activity of omega-3 fatty acids against epilepsy-induced hippocampal damage: quantification with immunohistochemical for calcium -binding proteins. Epilepsy Behav. 2008;13:3642, doi: 10.1016/j.yebeh.2008.01.001.

45. Cysneiros RM, Ferrari D, Arida RM, Terra VC, de Almeida AC, Cavalheiro EA, et al. Qualitative analysis of hippocampal plastic changes in rats with epilepsy supplemented with oral omega-3 fatty acids. Epilepsy Behav. 2010;17:33-8, doi: 10.1016/j.yebeh.2009.11.006.

46. Scorza FA, Cysneiros RM, Arida RM, Terra-Bustamante VC, de Albuquerque M, Cavalheiro EA. The other side of the coin: Beneficiary effect of omega-3 fatty acids in sudden unexpected death in epilepsy. Epilepsy Behav. 2008;13:279-83, doi: 10.1016/j.yebeh.2008.04.011.

47. Bourre JM. Omega-3 fatty acids in psychiatry. Med Sci. 2005;21:216-221.

48. Bourre JM. Roles of unsaturated fatty acids (especially omega-3 fatty acids) in the brain at various ages and during ageing. J Nutr Health Aging. 2004;8:163-74.
49. Mazza M, Pomponi M, Janiri L, Bria P, Mazza S. Omega-3 fatty acids and antioxidants in neurological and psychiatric diseases: an overview. Prog Neuropsychopharmacol Biol Psychiatry. 2007;31:12-26, doi: 10.1016/j. pnpbp.2006.07.010.

50. Smith KM, Sahyoun NR. Fish consumption: recommendations versus advisories, can they be reconciled? Nutr Rev. 2005;63:39-46, doi: 10.1111/ j.1753-4887.2005.tb00120.x.

51. Jeejeebhoy KN. Benefits and risks of a fish diet--should we be eating more or less? Nat Clin Pract Gastroenterol Hepatol. 2008;5:178-9, doi: 10. 1038/ncpgasthep1067.

52. Clarkson TW, Magos L, Myers GJ. The toxicology of mercury-current exposures and clinical manifestations. N Engl J Med. 2003;349:1731-7, doi: 10.1056/NEJMra022471.

53. Anonymous. Fish: friend or foe? In addition to heart-healthy omega-3 fats, seafood can carry mercury and other toxins. For most people, the benefits of eating fish far outweigh the risks. Harv Heart Lett. 2007;17: 4-6.

54. Domingo JL. Omega-3 fatty acids and the benefits of fish consumption: is all that glitters gold? Environ Int. 2007;33:993-8, doi: 10.1016/j.envint. 2007.05.001.

55. Scorza FA, Cysneiros RM, Arida RM, Terra VC, Machado HR, Rabello $\mathrm{GM}$, et al. Fish consumption, contaminants and sudden unexpected death in epilepsy: many more benefits than risks. Braz J Biol. 2010;70:665-70, doi: 10.1590/S1519-69842010000300026. 